Printer, 1864. Price 4s. 6d. See Part III, 'Quarterly Report on the Progress of Psychological Medicine.'

'Case of Degeneration and Atrophy of the Cerebrum, causing Unilateral Epilepsy.' By Kenneth M'Leod, A.M., M.D., Assistant Medical Oficer. Durham County Asylum, Sedgefield. Reprint from the 'Edinburgh Medical Journal,' October, 1864.

Dr. M'Leod here records with great minuteness a very interesting case of epilopsy, together with the post-mortem appearances illustrated by four plates.

'Public Health.' Sixth Report of the Medical Officer of the Privy Council, with Appendix, 1863. Presented pursuant to Act of Parliament. London, 1864, pp. 789.

We shall notice this able Report in the nest number of this Journah.

'Lunacy and Law, together with Hints on the treatment of Idiot3.' By T. E. D. Byrne, L.R.C.P. London, 1864, pamphlet, pp. 41.

The hists on the trealment of idiots ocoupy four pages; the rest of the pawahlet is filled with the story of the Flushing case, already familiar to our readers, and fully detailed in this year's Report of the Commissioners in Lunacy.

'The President's Address at the Thirty-second Annual Meeting of the British Medical Association, held in Cambridge, August, 1864. By George E. Paget, M.D. Cantab., \&c., pamphlet, pp. 31 .

'The Lunacy Acts: containing all the Statutes relating to Private Lunatics-Pauper Lunatics-Criminal Lunatics-Commissions of LunaoyPublic and Private Asylums-and the Commissioners in Lunacy. With an Introductory Comment, Notes to the Statutes, including References to Decided Cases, and a Copious Index.' By Danby P. Fry, Esq., of Lincoln's Inn, Barrister-at-Law, and of the Poor Law Board. Londan : Knight and Co., 90, Fleet Street, publishers by authority to the Poor-law Board, and to the Home Office, for the purposes of the Local Government Act, 1858. 1864, pp. 731. See Part II, Reoievos.

County Asylum Reports, 1864.

(Continued from the July number of the 'Journal of Mental Science.')

45. First Annual Report of the Argyll District Asylum for the Insane, 1864.

46. Annual Report of the York Lunatic Asylum for the year 1864 .

47. Report of the Committee of Visitors of the Lunatic Asylum for the counties of Bedford, Hertford, and Huntingdon, for the jear ending 3lst December, 1863.

48. Forty-fourth Annual Report of the Directors of the Dandee Royal Asylum for Lunatics, 20th June, 1864.

49. Annual Report of the Royal Edinburgh Asylum for the Insane, for the year ending 3lst December, 1863.

50. Thirty-fourth Annual Report of the Belfast District Hospital for the Insane Poor, 31st March, 1864.

51. Sixty-eight Report of the Friends' Retreat, near York, June, 1864.

52. Medical Report of the Royal Lunatic Asylum, Aberdeen, for the year ending 31st December, 1863.

53. Report of the Medical Superintendent of the Norfolk Lunatic Asylum, for the ycar ending 1863 . 
54. Report of the Sligo and Leitrim Hospital for the Insane, for the year 1863.

55. Twenty-fourth Annual Report of the Crichton Royal Institution Hospital for the Insane, Dumfries, November, 1863.

56. Fourth Annual Report of the Longview Asylum, State of Ohio, for the year ending December, 1863

57. Report of the Armagh District Lunatic Asylum, ending 31st December, 1863.

58. Dorset County Lunatic Asylum Report for the year 1863

59. Report of the Lunatic Asylum of the North and East Ridings of York shire, 23rd December, 1863.

60. Annual Report of the State Lunatic Asylum, Pennsylvania, ending December, 1863.

61. Annual Report of the Royal Lunatic Asylum, Montrose, for the year 1864.

62. Twelfth Annual Report of the Derbyshire County Lunatic Asylum,

January Sessions, 1864.

\section{Société Medico-Psychologique.}

At a meeting of the Sociéte Medico.Psychologique of Paris, Dec. 26th, 1864, the following gentlemen were unanimously elected - on the motion of Dr. Jules Falret-honorary members of the societ.y -Drs. Roller, Damerow, Griesinger, Lockhart Robertson, Maudsley, Mundy, Harrington Tuke, and Fleming.

\section{Appointments.}

Robert A. Davis, M.D., L.R.C.P., has been appointed Resident Medical Superintendent of the New Asplum for the county of Stafford, at Burntwood.

E. Jeffrey, M.R.C.S.E., has been appointed Assistant-Medical Officer to the Stafford County lunatic Asylum, vice R. A. Davis, M.D., appointed Medical Superintendent of the New Asylum for the County of Stafford, at Burntwood.

W. Rayner, M.R.C.S.E., has been appointed Assistant-Medical Officer to the Stafford County Asylum.

J. H. Simpson, L.R.C.P.I., late Assistant-Medical Officer at the Kent County Lunatic Asylum, Barming Heath, Maidstone, has been appointed Assistant-Medical Officer at the Gloucester County Lunatic Asylum, Wotton.

J. W. Warburton, M.R.C.S.E., has been appointed Assistant-Medical Officer to the County Asylum, Lancaster.

F. Wilton, M.R.C.S.E., Assistant-Medical Officer at the Gloucester County Lunatic Asylum, has been appointed Resident Medical Superintendent to the Carmarthenshire, Pembrokeshire, and Cardiganshire new Joint Lunatic Asylum at Carmarthen.

Sir Alexander Morison's Lectureship on Mental Disease at the Royal College of Physicians of Edinburgh. - Sir Alexander has endowed a lectureship on mental disease with $\mathcal{L} 50$ a year, at the Edinburgh College of Physicians. He has nominated Dr. William Seller as the first lecturer. The lectures, six in number, will be delivered in the College Hall, in June, free of charge to the profession.

Dr. Seller, a late President of the College, is well known in Edinburgh for his great learning in every department of medical literature. 